\title{
The Development of Intelligent Service System for Machine Tool Industry
}

\author{
Yueh-Ling Lin*, Chih-Chieh Lin, and Hung-Sheng Chiu \\ Central Industry Research \& Service Division, CID, \\ Institute for Information Industry, \\ 7 Guangming Road, Chung Hsing New Village, \\ Nantou City, Nantou County, Taiwan 54071, ROC \\ yuehlin@iii.org.tw erir@iii.org.tw bbchiu@iii.org.tw
}

\begin{abstract}
Developing efficient services for Taiwan's machine-tool industry is important because of the intelligent service enhancement for industrial networks and systems integration. The purpose of this study is to provide innovative service via remote cloud computing for machine tool solutions. The intelligent system integrates both hardware and software functions of five modules of machine tools (axes, controller, PLC, machine tools, sensors). A platform was developed for machinery information convergence and intelligent service system. In order to complete the standards for the proposed intelligent service system, the Taiwan Machine Tool Connect (TMTC) standards for precision machinery industry was developed to provide over $80 \%$ data acquisition support for current CNC machines and PLC controllers. Compare the TMTC standard with the MTConnect standard, the TMTC can provide faster and lower traffic on multi-trip data exchange to accelerate the interpretation and increase $50 \%$ transmission speed. The proposed system was demonstrated by applying it to the aerospace and automotive industries. The system performance was verified by proximal system functional test, platform functional verification, work and service process feasibility assessment, and key performance evaluation for machine tool solutions. The outcomes include three major results: (1) Successfully connect 302 machines with ServBox to achieve realtime machine monitoring and enhance productivity. (2) Establish a spin-off company to create machinery adaptive lease through its new business model by providing machinery data analysis, intelligent service, and applications for complementing the value chain of the overall machine tool solutions. (3) Improve industrial profits and increase production values for Taiwan's machine-tool industry.
\end{abstract}

Keywords-Taiwan Machine Tool Connect (TMTC) standards; Information and Communication Technology (ICT); machine tool solution; MTConnect (Manufacturing Technology Connectivity); machine tool industry; intelligent service system; ServBox; machinery networks; remote cloud computing; machinery adaptive lease

\section{INTRODUCTION}

For decades, the world machine-tool output and consumption have continuously increased. According to TMBA [1], Taiwan is currently one of the Asia's most important exporters of machine tools as well as the third-largest machine tool exporter in the world. With more than 200 machine-tool builders and 1,400 component makers, more than 40,000 CNC machine tools were sold every year throughout the world [2]. Taiwan as a manufacturing center for precision machinery, metalworking, information and communication technology (ICT), and warehousing, etc. makes the manufacturing become the key for Taiwan's economic development.

For 2012 Japan Machine Tool Show (JIMTOF) [3], machinery manufacturers illustrate the importance of integrating ICT and application software to achieve intelligent management and remote maintenance for facilitating product development process. The requirements for machine operations have become more complicated in recent years, and manufacturers are facing challenges to organize products, services, customers, and agents together to deliver appropriate solutions. At EMO Hannover 2013 [4], the devices such as DMG-Mori [5] and OKUMA [6] were presented to demonstrate the intelligent assistant functions for machine operation. The intelligent solutions can monitor, test and assure the efficiency, quality, and flexibility of machine tools to achieve manufacturing production and quality goals [7].

For the next generation of manufacturing, the concept of Industry 4.0 ensures "Intelligence in Production" is the key for intelligent machines to communicate with control and management systems autonomously to fulfill every task $[8,9]$. In general, the important elements for manufacturing technology concern about machines, tools, processes, software, and control system $[10,11]$. To provide cost-effective products across the manufacturing value chain, an efficient system for planning, control, and testing is necessary to ensure production quality and efficiency during operating process. Therefore, the development of an innovative-intelligent system can help machine operators to meet their desires and fulfill their needs.

Although there are a lot of self-development softwares among major machinery factories, the rich information among these machines cannot connect to each other while operating at the same time in the surrounding areas [12, 13]. Some application software developers develop limited application 
service only used in specific machines [14]. It's difficult to combine the whole information from separate machines with different brands (Siemens, Mitsubishi, Omron, GE Fanuc, Rockwell, Schneider, and Modicon, etc.). The lack of a common intelligent system with the same architecture and communication standard is a big problem.

This problem attributed to the use of different CNC controllers, self-developed PC board, or PLC drivers. The lack of intelligent service platform for machinery manufacturing factory makes it hard to collect information such as the production data from machines just in time. In order to solve the problem mentioned above, this study develops a platform for machinery information convergence and intelligent service system. With the intelligent service development, the intelligent system can provide middleware service for industrial networks and system integration. Finally, the intelligent system is useful to provide the overall machine tool solutions for machinery manufacturers to enhance efficient services.

\section{METHOD}

\section{A. Develop a Platform for Machinery Information Convergence and Intelligent Service System}

This study develops a new device, ServBox ${ }^{\circledR}$ [15], for machinery information convergence and intelligent service system development. ServBox ${ }^{\circledR}$ is a revolutionary service channel that can be used as a bridge to connect CNC machine

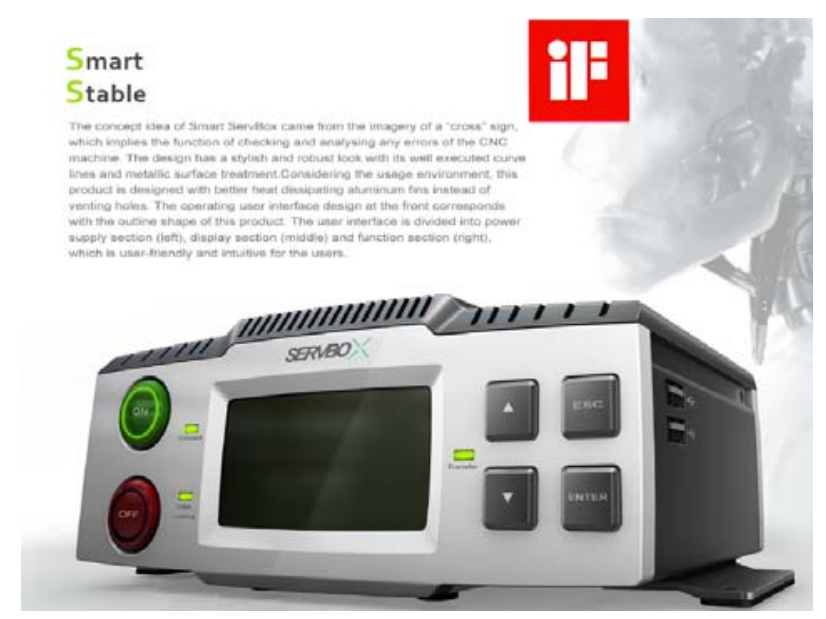

Figure 1. The ServBox ${ }^{\circledR}$ won the 2011 iF Product Design Award [16].

tools and machinery manufacturing factories with the remote service platform, as shown in Fig. 1. The design of ServBox ${ }^{\circledR}$ has a stylish and robust look with excellent heat dissipating aluminum fins. This product won the $2011 \mathrm{iF}$ Product Design Award from 2,756 competitors, out of 43 counties [16]. The user interface is divided into three parts including: (1) power supply section on the left side, (2) display section on the middle side, and (3) function section on the right side, which is userfriendly and intuitive for the users.

The ServBox ${ }^{\circledR}$ provides intelligent service for industrial networks and systems integration. This intelligent service delivers innovative cloud computing service, tandems machines to form machine networks for real-time industrial application, and provides remote production management. Besides, this device, ServBox ${ }^{\circledR}$, is a multi-controller data acquisition device which supports CNC controller, PLC OPC UA Adapter, application service development tool set, adaptability saving engine, and application service decentralized execution engine. Moreover, the ServBox ${ }^{\circledR}$ has computation and diversion mechanisms, multi-frequency highspeed data synchronization, and multi-node service operation and data convergence technology.

\section{B. Complete Taiwan Machine Tool Connect (TMTC) Standards}

In order to complete the standards for the proposed intelligent service system, common parameters including five modules of machine tools (axes, controller, PLC, machine tools, sensors) used by a total of 59 machinery manufacturers were considered within this service system. Fig. 2 illustrates the TMTC standards and parameter structures. Through ServBox ${ }^{\circledR}$, it can provide synchronized communication between CNC machine tool and the remote service platform for machine tool builders. Machine tool builders can deliver intelligent service and industrial network via remote cloud computing to increase productivity by providing instant check and solutions.

The TMTC setting uses Binary format and TCP/IP transport protocol which are faster and lower traffic on small data packets. Compare with the current American MTConnect XML and HTTP standard, the TMTC can provide a reverse signal written (CNC parameter writing \& PLC parameter writing) and multi-trip data exchange by using two-bit packet transmission to accelerate the interpretation and transmission speed. And, the TMTC increases 50\% transmission speed as listed in Table 1.

Based on the multi-controller data acquisition device, ServBox ${ }^{\circledR}$, this multi-controller completes eight types of CNC controller Adapter which common used by Fanuc, Siemens, Heidenhain, Mitsubishi, Syntec, Pou-Yuen Tech, Intek, and Hurco Automation, etc. The multi-controller is useful for commercial application because the coverage rate is over $80 \%$ of domestic brands of controllers on machine tool market. Table 2 lists the controller brands support by PLC OPC UA Adapter. The result shows a total of $85.7 \%$ commercial available. 


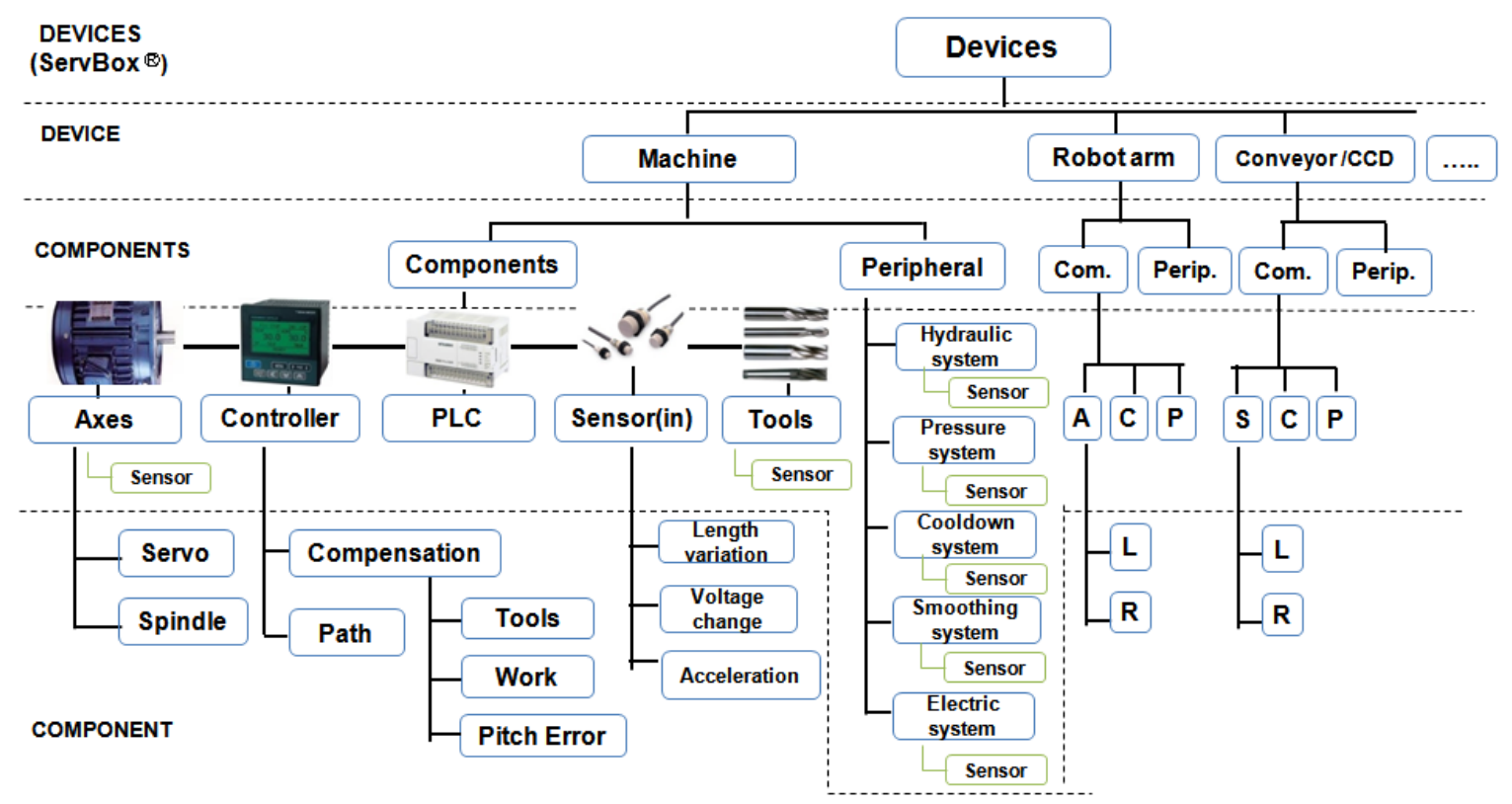

Figure 2. Taiwan Machine Tool Connect (TMTC) standards and parameter structures [17].

\section{Process for Intelligent Service Development}

The intelligent service system can retrieve data across controllers and provide users basic tools for files, strings, matrices, math, and signal analysis, etc. The built-in analysis tool can be used directly with friendly user interface to generate real-time machine data. To accelerate data storage and retrieval speed, the intelligent service system has database for both relational data storage and non-relational data storage. To provide correct and fast data for web query, it takes about five seconds to receive data less than 20GB. And, the raw data can be saved and stored up to 90 days or more. In addition, the execution process of the intelligent service system can provide graphical charts and be recorded by the macro database. The process for developing the intelligent service system is illustrated in Fig. 3.

TABLE I. COMPARE THE PERFormanCE OF TMTC WITH MTCONNECT [17].

\begin{tabular}{|l|c|c|}
\hline & $\begin{array}{c}\text { TMTC } \\
\text { OPC UA Adpater }\end{array}$ & $\begin{array}{c}\text { MTC OPC UA } \\
\text { Gateway }\end{array}$ \\
\hline CNC parameter writing & Yes & No \\
\hline CNC parameter reading & Yes & Yes \\
\hline PLC parameter writing & Yes & Yes \\
\hline PLC parameter reading & Yes & Yes \\
\hline Transmission speed & 2 processes & 4 processes \\
\hline Transport protocol & TCP/IP & TCP/IP \\
\hline File format & Binary & Binary + XML \\
\hline
\end{tabular}

Test under the environment of Intel Atom 1.6GHz/1GB RAM/4GB storage IPC to test 22 parameters write/read with 12 PLC controllers.

Identify applicable sponsor/s here. (sponsors)
To solve the problem as increasing the number of machines, it will result in the decreased efficiency. The intelligent system proposed a distributed execution service to perform the same application service simultaneously through distributed multinode method. In this way, the machine computation time decreases from $160 \mathrm{~ms}$ to $120 \mathrm{~ms}$ as listed in Table 3. This distributed execution service improves 25\% operation performance and enables the service system available for more machines. Take FactoryWize for example [18], currently the numbers of machines handled by one single host computer of FactoryWize are 512 machines. With this distributed execution service, the numbers of machines can upgrade $25 \%$ and reach up to 640 machines.

TABLE II. THE CONTROLLER BRANDS SUPPORT BY PLC OPC UA ADAPTER [19].

\begin{tabular}{|l|c|c|}
\hline Controller Brands & Server Series & $\begin{array}{c}\text { Market } \\
\text { Coverage Rate }\end{array}$ \\
\hline Siemens & OPC Server & $30.70 \%$ \\
\hline Mitsubishi & OPC Server & $13.90 \%$ \\
\hline Omron & OPC Server & $6.60 \%$ \\
\hline $\begin{array}{l}\text { GE } \\
\text { Fanuc }\end{array}$ & $\begin{array}{c}\text { OPC Server } \\
\text { FOCAS OPC Server }\end{array}$ & $4.00 \%$ \\
\hline Rockwell & OPC Server & $21.60 \%$ \\
\hline Schneider & OPC Factory Serve & $8.90 \%$ \\
\hline Modicon & Modbus OPC Server Suite & N/A \\
\hline Siemens & OPC Server & $30.70 \%$ \\
\hline Total & & $\mathbf{8 5 . 7 0} \%$ \\
\hline
\end{tabular}




\section{Provide Intelligent Service to Complement the Value Chain Gaps}

The reason why the service system is still on the value chain scission is because of the lack of two types of service technologies including machinery data acquisition and production data analysis [20], as shown in Fig. 4.

\section{E. Demonstrate the Intelligent Service System by Applying it to the Aerospace and Automotive Industries}

The proposed intelligent service system was demonstrated by applying it to the aerospace and automotive indudstries. The intelligent system can be used for data acquisition, temporary storage, diversion, transmission, and platform operation under various kinds of rules. Additionally, the intelligent system provides multi-tools to help the quality assurance service, the maintenance/repair service, the productivity management service, and the machine energy efficiency service.

\section{F. Develop Monitoring System for Wheels Mechanism Process}

The development of the intelligent service system focuses on the aspect of market application. The representative automobile company in Taiwan applies this intelligent service system to the wheel products application in the automobile industry. In order to develop monitoring system for wheels mechanism process, the intelligent service system connects three CNC machines, three quality detectors, and one six-axis robot arm to form a flexible manufacturing unit, as illustrated in Fig. 5.

\section{RESULTS AND DisCUSSIONS}

Due to the complex supply chain systems and diverse product categories of precision machinery industries, it's difficult to integrate the whole process and product information through various production environments. The research shows the precision machinery industries presenting with extreme weakness in both information and communication technology (ICT) application and intelligent service. Through the years, we continue to make efforts to demonstrate the importance and feasibility of the intelligent service, and the research results have become the key demands of precision machinery industry.

The study found evidence in the intelligent service system to solve the problem caused by precision machinery manufacturers. To integrate information retrieval process from machinery equipment manufacturers and analyze production information from machine tool providers, the appropriate hardware and software functions are combined and worked together for the intelligent service system. Based on information and communication technology (ICT) application, the service practice is combined with the development of intelligent service in machinery industry to provide machinery data analysis, value-added service, and applications for the overall machine tool solutions. Mobility management solutions and big data modal analysis are done completely in this study for improving the production utilization rate. The intelligent service system not only improves the production utilization rate and service added value, but also helps manufacturers to do further $R \& D$ researches.

\section{A. Provide Machine Tool Solutions for Precision Machinery Industry}

To enhance the intelligent service of the machinery equipment, the system verifications were done directly with 302 machines connected together at the same time. The connections of these 302 machines are from 15 manufacturers in Taiwan including: (1) Victor Taichung Machinery Works

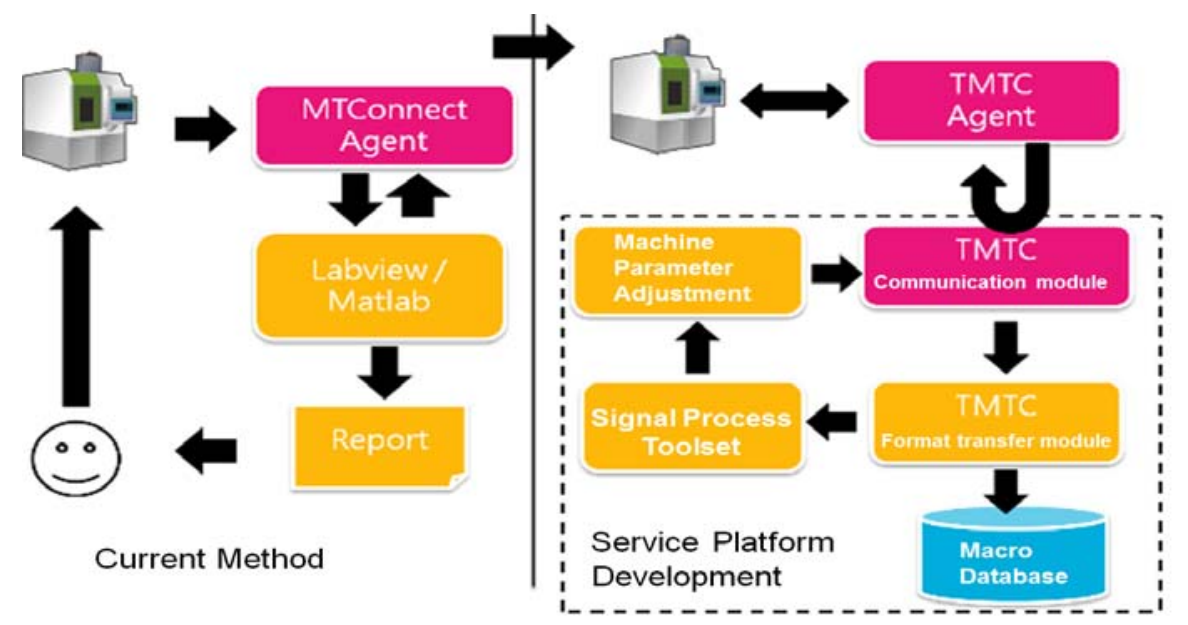

Figure 3. The process for intelligent service platform development [21]. 


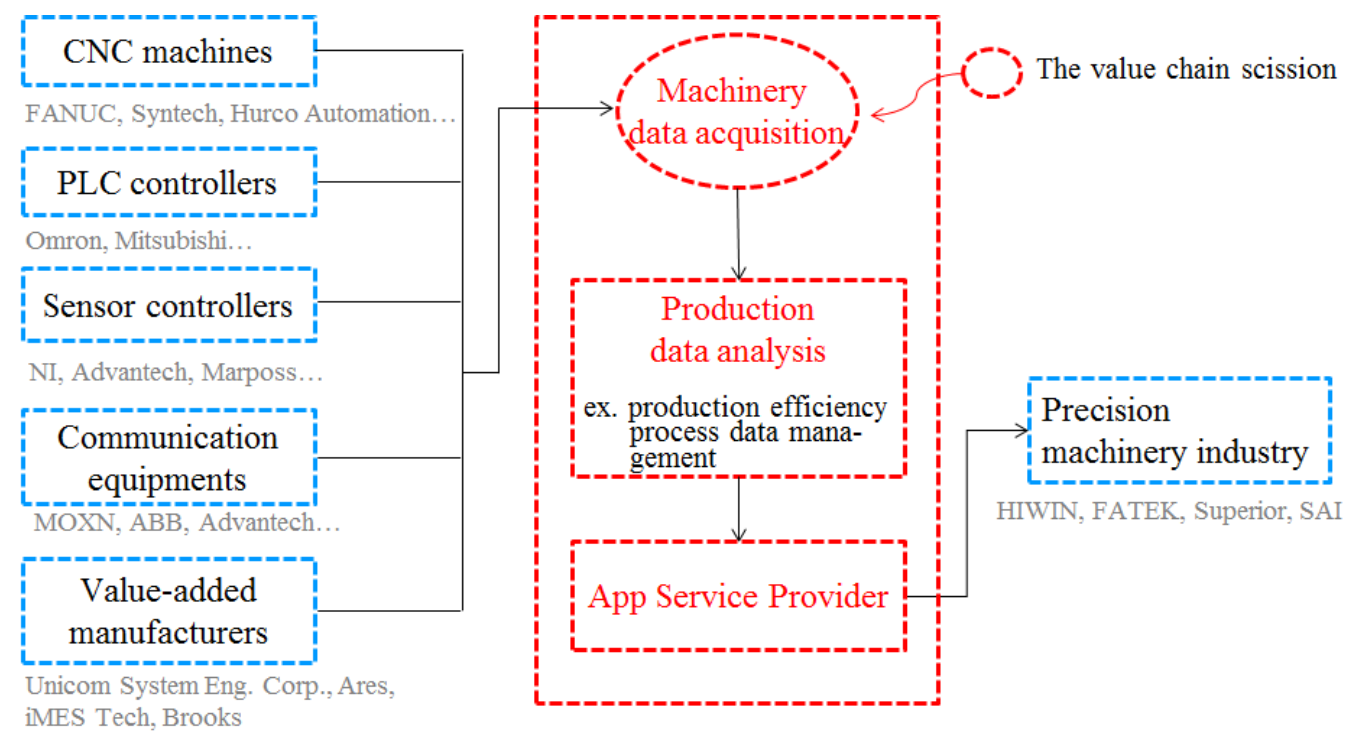

Figure 4. The value chain gap analysis of the intelligent service for precision machinery industry [22].

Company, (2) Taiwan Steady Precision Company, (3) Fatek Technology Company, (4) Car wheel rim factory, (5) Superior, (6) Far East Machinery Company, (7) Syntec Company, (8) Spring plant, (9) Aluminum alloy wheel factory, (10) Shoe factory, (11) Dali Machinery Company, (12) SIMTECH, (13) Hurco Technology, (14) Taiwan Takizawa Technology, and (15) Formosa Company.

\section{B. Provide Intelligent Service Application}

Based on the machine tool solutions, three licenses are transferred successfully to the leading manufacturers of precision machinery industry with total amount of 631.88 thousand NT. dollars. And, the idea for machinery adaptive lease promotes intelligent service to manufacturers step by step for attracting their willingness to invest. Three manufacturers made investments with the service including: (1) Fatek Technology Company (for expansion drive wheel mechanism and monitoring performance), (2) Victor Taichung Machinery Works Company (for extending processing efficiency and fault analysis function of cloud digital factory), (3) Cosen Mechatronics Company (for machinery cloud platform). The intelligent service system not only brought steady incomes to increase productivity, but also provided manufacturers sell more customized machines with total amount of 81,900 thousand NT. dollars.

\section{Establish a New Spin-off Company}

A new spin-off company is established to develop a business model to manipulate integrating for the tandem value chain. This company constructs its new business model and sales pipeline by providing machinery data acquisition, analysis, intelligent service, and applications for complementing the value chain of the overall machine tool solutions and broadening the base of precision machinery service. The company proposes a novel idea for machinery adaptive lease as a new business model with more appropriate and flexible prices. With machinery adaptive lease, the machinery manufacturers do not need to invest lots of fixed costs in the beginning. The initial investment will reduce and adjust with more suitable and flexible prices for the machinery adaptive lease of the intelligent service system. Thus, the machinery manufacturers can manage the costs according to various needs from machine tools and production lines.

TABLE III. THE COMPARISON OF EXECUTION SERVICE EFFICIENCY THROUGH MULTI-NODE [19].

\begin{tabular}{|l|c|c|}
\hline & $\begin{array}{c}\text { Original } \\
\text { Application Service }\end{array}$ & $\begin{array}{c}\text { Distributed } \\
\text { Execution Service }\end{array}$ \\
\hline Number of node & 1 & 3 \\
\hline $\begin{array}{l}\text { Data acquisition } \\
\text { and computation time }\end{array}$ & $160 \mathrm{~ms}$ & $120 \mathrm{~ms}$ \\
\hline \multicolumn{2}{|l|}{ Test under the environment of Intel C2Q 2.4GHz/4GB RAM/300GB storage to test industrial }
\end{tabular}

Test under the environment of Intel C2Q 2.4GHz/4GB RAM/300GB storage to test industrial production and capacity utilization for 300 machines. 


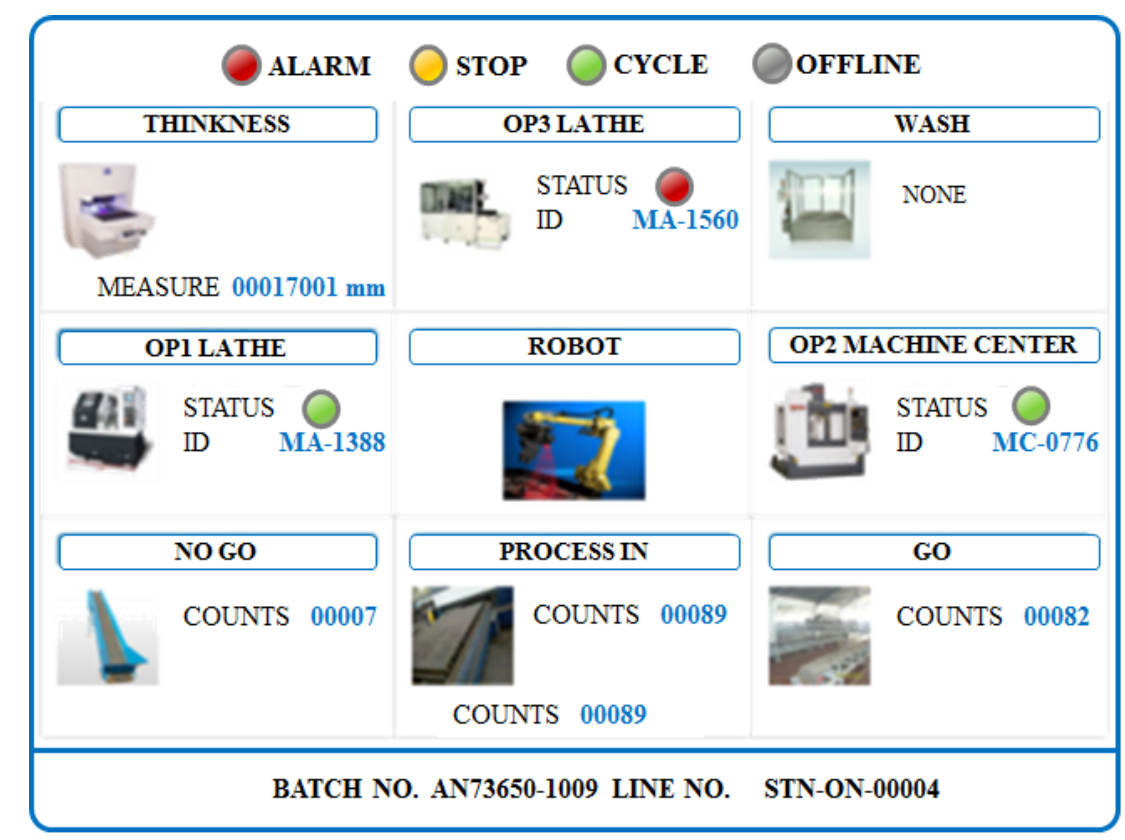

Figure 5. The monitoring system for wheels mechanism process [15].

\section{CONCLUSION}

Developing efficient services for Taiwan's machine-tool industry is important because of the intelligent service enhancement for industrial networks and systems integration. The purpose of this study is to provide innovative service via remote cloud computing for machine tool solutions. This study cooperate with production management consultant team to make sure the research outcomes effectively combine domain knowledge of advanced manufacturing technology with information and communication technology (ICT) applications. The useful experience from the consultant team continue help us improve the related knowledge and build correlated interaction with precision machinery industry. The ongoing expansion plan enhances training and counseling for machinery manufacturers to keep improve controllability and expand the visible performance.

For increasing international visibility, we have achieved excellent technical cooperation with the intelligent maintenance system research center of the United States National Science Council. Also, we have won the Cloud Technology Platform Award of P\&G (Procter \& Gamble Company) issued by global technical director Eric Burg on the $25^{\text {th }}$ IMS IAB conference on May, 2013. Being renowned by famous international manufacturers including: U.S. Boeing, GE, Applied Materials, GCWW, Japan OMRON, ISID, and Korea Samsung, etc. This intelligent service system with an innovative start-up creates a significant global presence which helps to increase the international competitive position.
Furthermore, by cooperating with domestic machinery and control departments at school, 588 students got trained with this intelligent service system. In this way, it not only nurtures students' talents, but also enhances the growth of the development of this intelligent service system in industry.

\section{ACKNOWLEDGMENT}

This study is conducted under the "2015 Project of Development of Industrial Platform for Value-Added Service via Intelligent Sensing Technology (2/4)" of the Institute for Information Industry which is subsidized by the Ministry of Economy Affairs of the Republic of China.

\section{REFERENCES}

[1] Taiwan Machine Tool \& Accessory Builders' Association (TMBA), http://www.tmba.org.tw

[2] TMTS 2014-Taiwan International Machine Tool Show 2014 for Tools \& Tooling Equipments, Plant \& Machinery, http://www.tmts.tw

[3] 2012 Japan Machine Tool Show (JIMTOF), http://www.jimtof.org/2012/eng/outline.html

[4] EMO Hannover 2013, http://www.emo-hannover.de/home

[5] DMG-MORI, http://www.dmgmori.com/webspecial/journal_2013_1/ennp/celos-apps.htm

[6] OKUMA, http://www.okuma.com

[7] International Digital Publishing Forum, http://www.idpf.org 
[8] German Research Centre for Artificial Intelligence, Industry 4.0: From the Internet of Things to Smart Factories.

[9] Z. Bi, L. D. Xu, and C. Wang, "Internet of Things for Enterprise Systems of Modern Manufacturing,” IEEE Transactions on Industrial Informatics, vol. 10, issue 2, 2014, pp. 1537-1546.

[10] Solution Architecture for Industry 4.0, BOSCH, 2013.

[11] L. Zhang, Y. Luo, F. Tao, B. H. Lia, L. Ren, X. Zhang, H. Guo, Y. Cheng, A. Hu, and Y. Liu, "Cloud manufacturing: a new manufacturing paradigm,” Enterprise Information Systems, vol. 8, issue 2, 2014, pp. 167-187.

[12] F. Tao, Y. Cheng, D. L. Xu, and L. Zhang, "CCIoT-CMfg: Cloud Computing and Internet of Things-Based Cloud Manufacturing Service System,” IEEE Transactions on Industrial Informatics, vol. 10, issue 2, 2014, pp. 1435-1442.

[13] Q. Ning, T. Wang, L. Liu, and Y. Jiang, "Research on CNC Machine Tools Integration Condition Monitoring System and Its Information Exchange Technology,” Future Computing, Communication, Control and Management, Lecture Notes in Electrical Engineering, vol. 144, 2012, pp. 441-450.
[14] A. Gupta and V. U. Srinivasa, "Black Box for Machine Tools: Based on Open CNC Architecture Control Systems,” ACEEE Int. J. on Control System and Instrumentation, vol. 3, no. 1, 2012, pp. 6-10.

[15] ICT Standards and Intelligent Service Platform Development, Ministry of Economic Affairs in Taiwan, Annual Report, 2013, pp. 16-17.

[16] IF Design Award, http://www.ifdesign.de/awards_index_e

[17] MTConnect Institute, MTConnect-OPC UA Companion Specification DRAFT Version 1.0, 2011, pp. 12-20.

[18] FactoryWize, http://www.factorywiz.com

[19] Precision Machinery Service Development: Machine Tool Solution and Service Verification, Ministry of Economic Affairs in Taiwan, Annual Report, 2014, pp. 32-36.

[20] Industry Intelligent Sensing Service Platform Development, Ministry of Economic Affairs in Taiwan, Midterm Report, 2014, pp. 47.

[21] ICT Standards and Intelligent Service Platform Development, Ministry of Economic Affairs in Taiwan, Annual Report, 2013, pp. 54-55.

[22] Precision Machinery Service Development: Machine Tool Solution and Service Verification, Ministry of Economic Affairs in Taiwan, Annual Report, 2014, pp. 22-23. 